\title{
Diabetic Neuropathy - Nerve Morphology in the Upper Extremity
}

\author{
Niels Thomsen, Anders Bjorkman \\ and Lars B. Dahlin \\ Department of Hand Surgery, Skåne University Hospital \\ Lund University \\ Sweden
}

\section{Introduction}

Diabetic neuropathy is the most common long-term complication of Type 1 and Type 2 diabetes, affecting approximately $10 \%$ within a year of diagnosis to $50 \%$ of subjects with diabetes for more than 25 years. Prevalence rates depend on diagnostic technique and the population under study (Dahlin et al., 2011; Rubino et al., 2007). Diabetic neuropathy associated with Type 1 diabetes tend to be more frequent, and develop more rapidly than in Type 2 diabetes. Gender differences seem to exist with males being more affected by neuropathy than females (Booya et al., 2005; Aaberg et al., 2008). Diabetes mellitus imposes a considerable burden on the nervous system and is the most common cause of peripheral nerve damage associated with a vast spectrum of neuropathy syndromes. The primary risk factor for the development of diabetic neuropathy is related to duration and severity of hyperglycaemia. Other independent risk factors for diabetic neuropathy include hypertension, hypercholesterolemia, smoking, increased body mass index and the presence of other complications of diabetes such as retinopathy and nephropathy (Adler et al., 1997). Diabetic neuropathy affects somatic as well as autonomic neurons of the peripheral nervous system with resultant morbidity and mortality for the patients and economic cost for the society and health care system. Interactions of pathogenic metabolic and vascular factors are responsible for the development of diabetic neuropathy. These complex mechanisms, which are not fully understood, need further clarification in order to develop new treatment strategies. The aim of this chapter is to describe methods and result in the evaluation of small and large nerve fibre pathology on the upper extremity.

\section{Small nerve fibre morphology}

Epidermal nerve fibres are predominantly unmyelinated C-fibres, which originate from the dorsal root ganglion, and are responsible for conveying thermal and nociceptive painful sensation. Small nerve fibres are believed to degenerate early in the course of diabetic neuropathy, and may even be affected in patients with impaired glucose tolerance (Loseth et al., 2008; Nebuchennykh et al., 2008). 
An accepted method to evaluate small nerve fibre pathology is quantification of intraepidermal nerve fibre density (IENFD) using immunostaining with the cytoplasmatic neuronal marker protein gene product 9.5. In accordance with recommendations from the European Federation of Neurological Societies, the majority of studies report on results from the lower extremity (Lauria et al., 2005). It is generally believed that IENFD decreases with age, while the influence of gender seems controversial (Goransson et al., 2004). In healthy subjects, as well as in asymptomatic diabetic patients, a length dependent reduction of IENFD has been demonstrated (Umapathi et al., 2007). Using IENFD quantification at the ankle, the diagnosis of diabetic peripheral neuropathy was reported to have a sensitivity and specificity of about $75 \%$. Skin biopsy has been reported to be the most sensitive measure for pre-diabetic neuropathy compared to nerve conduction studies, quantitative sensory testing, and a neuropathy score system (Smith et al., 2006).

A reduction in unmyelinated nerve fibre density has been established from skin biopsies on the lower leg as well as from sural nerve biopsy of patients with diabetes. Sorensen et al. (2006) demonstrated a significantly lower IENFD in a group of patients with diabetes having painful neuropathy in the lower extremity compared to a group of patients without pain. Likewise, other reports from studies on the lower leg have indicated that a reduction in IENFD among patients with diabetes may primarily be related to those suffering from painful small fibre neuropathy (Quattrini et al., 2007). On the other hand, complete denervation of the epidermis can be seen in patients with genetic insensitivity to pain, questioning whether loss of IENF is related to pain, or should be judged only as an indicator of neuropathy (Nolano et al., 2000).

Studies of IENFD in the upper extremity are sparse and have shown divergent results. Based on skin biopsies from the distal forearm a considerably reduced IENFD was demonstrated in patients with neuropathy compared to a healthy control group (Chien et al., 2001). However, aetiologies behind the neuropathy patient group were mixed with only $14 \%$ of the cases being due to diabetes. Another study compared skin biopsies of the forearm and the lower extremity in patients with diabetes, patients without diabetes suffering from neuropathy of different origin, and in a healthy control group (Pittenger et al., 2004). They demonstrated a significant difference in IENFD in the distal leg, but not in the forearm comparing patients with healthy controls subjects.

Normative range of IENFD in the wrist area has been investigated in two studies. Using immunofluorescence and light microscopy on $15 \mu \mathrm{m}$ thick sections from skin biopsies of various areas of the hand an IENFD of $10.3 \pm 8.3 / \mathrm{mm}$ (mean \pm SD) in glabrous skin of the proximal palm was reported. It was noted that inter-individual variability was high and that no specific pattern of distribution was found from fingertips to the palm (Kelly et al., 2005). A study on hairy skin from the distal forearm, using bright-field immunohistochemistry on $50 \mu \mathrm{m}$ thick sections reported a higher IENFD of $17.3 \pm 6.2 / \mathrm{mm}$ (Pan et al., 2001). Whether the difference in these results are caused by the study population, quantification technique or morphology in the hairy and glabrous skin remains unanswered as no comparative study on IENFD at the same anatomical level was performed.

In a recent study with matched patient groups, skin biopsies taken from hairy and glabrous skin at wrist level, demonstrated no difference in IENFD between patient with and without diabetes (Thomsen et al., 2009b). Furthermore, no differences were found between patients with Type 1 or Type 2 diabetes, or between subgroups of patients with diabetes with or without peripheral neuropathy. In addition, for both patients with and without diabetes, 
IENFD was significantly higher in females compared to males and in hairy compared to glabrous skin. This is interesting, with the reported higher frequency of diabetic neuropathy in males than in females, suggesting that subjects with lower nerve fibre density would be more prone to develop neuropathy (Aaberg et al., 2008). Glabrous skin has been reported to have a higher heat pain threshold than hairy skin. Neurophysiological studies on monkeys

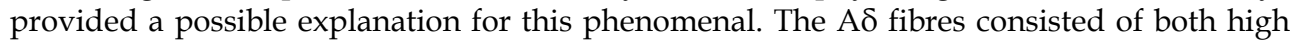
threshold heat nociceptors and low threshold heat nociceptors, with glabrous skin being

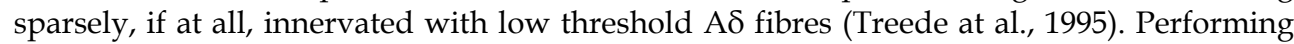
contact heat evoked potential stimulation others have confirmed these findings, that the glabrous surface of the hand is paucity innervated by low threshold nociceptors. These results on different nociceptive thresholds and receptors in glabrous versus hairy skin together with reported difference in thermal pain thresholds between male and female could explain these differences in the IENFD (Meh \& Denislic, 1994). Furthermore, in order to functionally balance important inputs to the exploring surface of the glabrous skin, it seems reasonable that density of intraepidermal nociceptive nerve fibres is lower compared to the hairy skin.

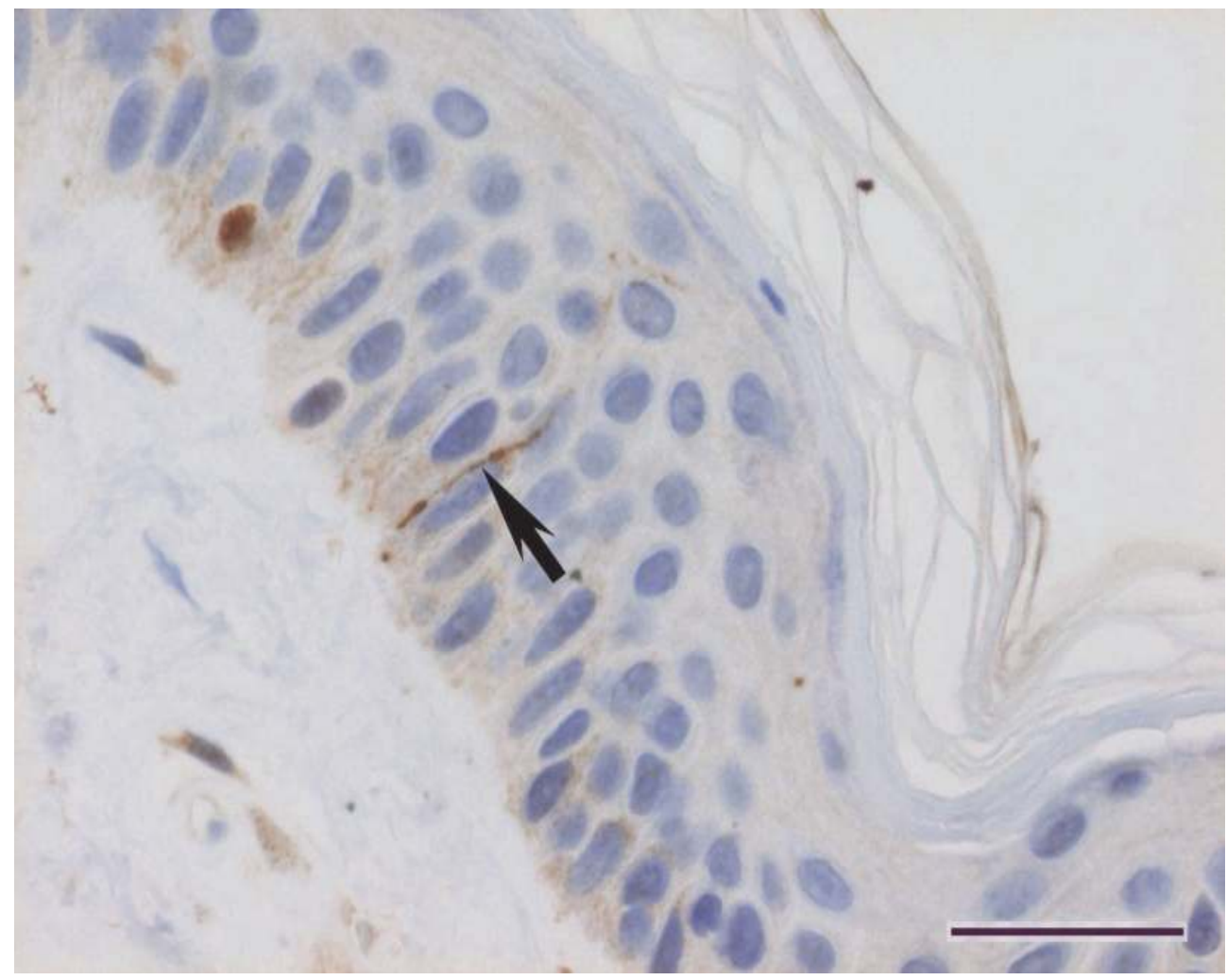

Fig. 1. Intraepidermal nerve fibre (arrow) from the dorsum of the wrist. Immunostained with protein gene product 9.5. Bar $=25 \mu \mathrm{m}$. 
Small nerve fibres can also be assessed from a sural nerve biopsy. However, the biopsy procedure may cause long-term discomfort for the patient (Dahlin et al., 1997) and evaluation requires access to electron microscopy. A study, where patients underwent skin as well as sural nerve biopsy, concluded that IENFD measurement in the skin was more sensitive than evaluation of sural nerve biopsy to identify small fibre neuropathy (Herrmann et al., 1999).

As a non-invasive method for assessment of neuropathy, corneal confocal microscopy allows in vivo visualization of small nerve fibres in the cornea without taking a biopsy (Quattrini et al., 2007). The extent of corneal nerve damage and repair can be accurately defined. Reduction in corneal nerve density has been demonstrated to correlate with the severity of somatic neuropathy defined by intraepidermal nerve fibre loss. Abnormalities have been detected in minimal and mild neuropathy. Furthermore, nerve regeneration and its response to therapy may be quantified by detecting changes in corneal nerve branch density and tortuosity.

\section{Large nerve fibre morphology}

Sural nerve biopsy has been the method of choice to undertake neuropathological assessment for the diagnosis of peripheral neuropathies of unknown cause. Biochemical analysis can be performed, such as assessment of sorbitol, fructose and myo-inositol levels, which relates to clinical neuropathy (Sundkvist et al., 2000). Furthermore, it has been used to gain insight to the underlying pathology of nerve damage in diabetes. Due to the potential complication following sural nerve biopsy (wound infection, persistent pain, dysaesthesia of the affected skin, sensory loss and patient dissatisfaction with the procedure), demonstrated for both type 1 and type 2 diabetes, such procedures should be restricted to carefully selected cases and performed at surgical centres with a special interest in this field (Dahlin et al., 1997). Nerve biopsies require careful managing and evaluation by an experienced neuropathologist. For obvious reasons, most of our insight into nerve pathology relies on experimental studies.

From evaluation of sural nerve biopsies, it is known that the principal pathological lesions in human diabetic neuropathy are axonal degeneration and regeneration with loss of large myelinated nerve fibres, and segmental demyelination (Veves et al., 1991; Malik et al., 2005). Endoneurial microangiopathy has been demonstrated in such biopsies including basement membrane thickening, pericyte degeneration, endothelial cell hyperplasia, and luminal narrowing. Myelinated nerve fibre density has proven a reliable indicator of neuropathy in diabetic patients, correlating with clinical findings as well as to nerve conduction studies (Malik et al., 2001). Furthermore, a low myelinated fibre density may predict future nerve fibre loss and progression of neuropathy with time (Thrainsdottir et al., 2009).

With progression of disease, diabetic neuropathy may also affect the upper limb, in particular the mononeuropathies. Owing to the described morbidity of a nerve biopsy, as well as the length-dependent nature of diabetic neuropathy, only a few publications describe morphology of nerves in the upper limb. Due to limitations in acquiring a biopsy, which fulfils the criteria for nerve biopsy in the upper limb, results have so far have been provided from post-mortem subjects or amputated limbs (Reske-Nielsen \& Lundbaek, 
1968). Furthermore, the number of included cases are small, predominantly paraffin sections with limited detailed quantification.

In a post-mortem study of subclinical entrapment of the median and ulnar nerves a thickening of the perineurium and epineurium were observed. Furthermore, teased fibre analysis revealed thinning and retraction of the myelin as well as intercalated segments, suggestive of previous demyelination (Neary et al., 1975). The limited amount of human nerve tissue available for analysis, make us reliant on experimental models in order to understand the pathological features of nerve compression. It is clear that animal models with application of compression clamps or silicon tubes around a nerve, however valuable, are not an authentic reflection of chronic nerve compression in humans. However, acute and chronic compression models may serve as prototypes for analysis of intracellular signalling in Schwann cells and neurons during and after nerve compression (Dahlin et al., 2008). Acute nerve compression differs from chronic nerve compression involving mechanisms such as inflammation, and stretching and tethering of the nerve during joint movements. Schwann cells are believed to be one of the primary mediators of demyelination seen in nerve compression, possibly initiated by mechanical stimulus (Gupta \& Steward, 2003).

Recently, a low morbidity procedure was presented, to assess large fibre pathology of the upper extremity (Thomsen et al., 2009a). The posterior interosseous nerve (PIN) biopsy is performed on the distal part of the dorsal forearm. The PIN is located on the interosseous membrane in the bottom of the fourth extensor compartment (Fig.2). A 3-4 cm long nerve biopsy can be harvested. Morphologic assessment of the PIN biopsies demonstrated a reduced myelinated nerve fibre density in patients with Type 2 diabetes compared to autopsy control subjects (Fig.2). It was argued that the PIN biopsy procedure fulfils the criteria for nerve biopsy described by Dyck (1968) as it has a constant location, is easy accessible, leaves no sensory or motor deficit and it is seldom subjected to trauma or entrapment. Furthermore, if a corroborative functional assessment is desirable, nerve conduction studies can be performed on the superficial sensory branch of the same nerve and at the same distal level as the nerve biopsy. The posterior interosseous nerve biopsy, performed under local anaesthesia and well tolerated by the patients, enables for the first time a larger scale human evaluation of nerve morphology in diabetes.

The posterior interosseous nerve biopsy performed on patients with carpal tunnel syndrome, demonstrated a significant reduction in myelinated nerve fibre and endoneurial capillary densities in patients with diabetes compared to patients without diabetes (Thomsen et al., 2009c). Surprisingly, these parameters were reduced for both patients with and without diabetes having carpal tunnel syndrome, compared to healthy control subjects without carpal tunnel syndrome. The finding suggests that distinct nerve pathology may exist even in patients without diabetes with idiopathic carpal tunnel syndrome. A reduction in endoneurial capillary density, which ultimately will lead to reduced endoneurial oxygenation, provides the first mechanistic foundation for axonal nerve damage through a hypoxic endoneural environment. A reduced number of nerve fibres may therefore represent an inborn impaired reserve capacity for the peripheral nervous system. Although not quantified, microangiopathy with reduplication of the basement membrane and thickening of the endothelium was observed in some of the diabetic patients. Gender differences need further investigation as a resent study on large nerve fibre function, represented by vibrotactile sense and electrophysiology demonstrated impaired function in males compared to females (Dahlin et al., 2011). 


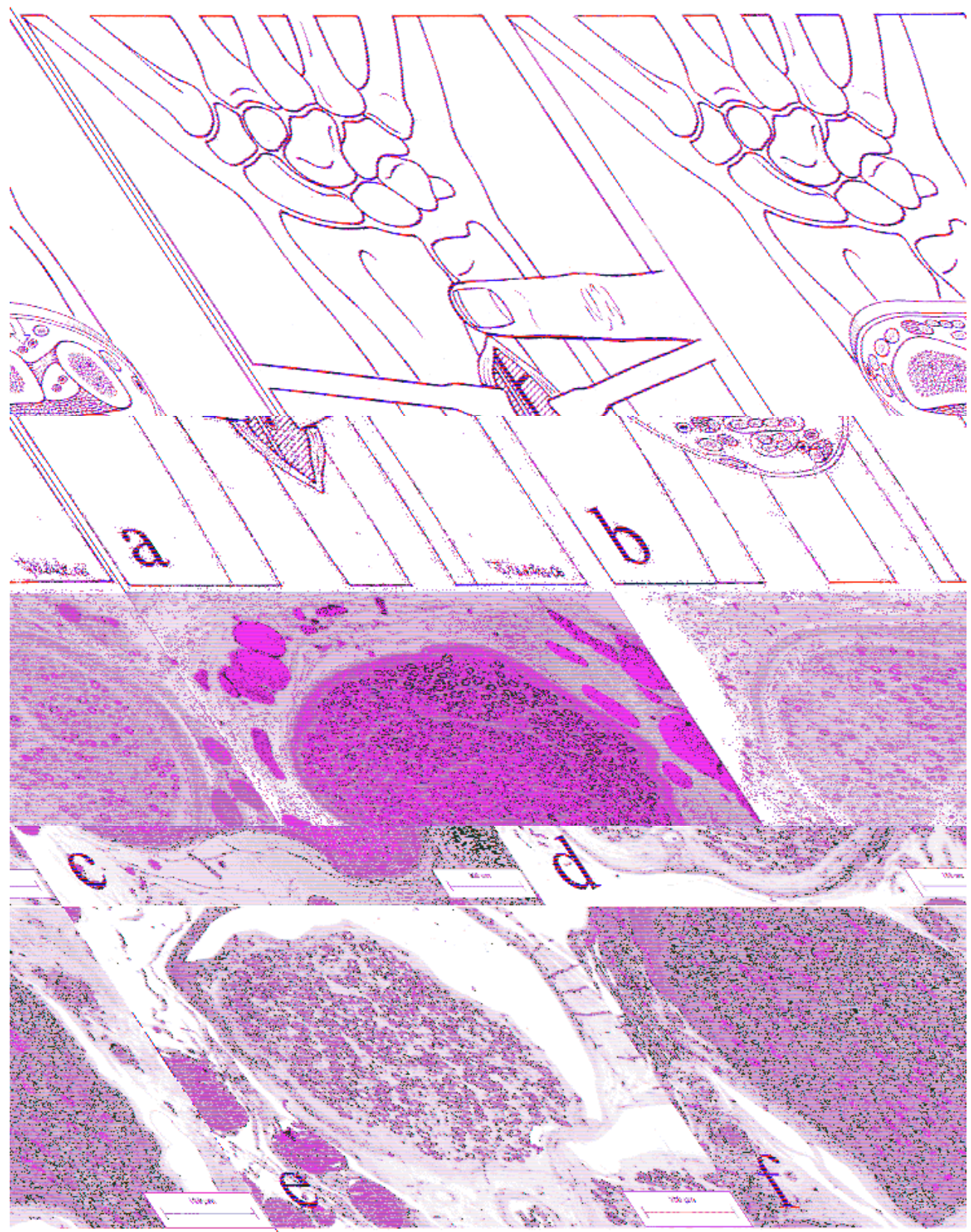

Fig. 2. Technique of the biopsy procedure. (a) Landmark for the incision is one fingerbreadth proximal to the ulnar head. The PIN and the anterior interosseous artery are seen on the interosseous membrane. (b) Cross-section of the distal forearm. The PIN (arrow) and the anterior interosseous artery are found in the bottom of the fourth extensor 
compartment lying on the interosseous membrane.Light microscopic image of a PIN fascicle from (c) an autopsy control subject and (d) a diabetic subject. Note the lower myelinated fibre density in the diabetic patient compared to the autopsy control. From another patient (e) a PIN fascicle and (f) a sural nerve fascicle. Observe the lower myelinated fibre density in the sural nerve fascicle compared to the PIN fascicle. Reproduced with the courtesy of Wiley-Blackwell.

\section{Conclusion}

When evaluating small nerve fibre pathology in the upper extremity it is important to consider that the intraepidermal nerve fibre density is higher in female than in males and higher in hair than in glabrous skin. Differences between patients with and without diabetes needs further attention.

Studies on nerve morphology in the upper extremity can provide useful insight into the pathophysiology of diabetic neuropathies. Patients with diabetes demonstrate significant reduction in myelinated nerve fibre and endoneurial capillary densities in the upper extremity compared to patients without diabetes. These factors may predispose patients with diabetes to compression neuropathy, which is found with increased prevalence compared to patients without diabetes.

\section{Acknowledgement}

The studies on diabetic neuropathy from our group was supported by the Swedish Research Council (Medicine), Crafoord's Fund for Medical Research, Svenska Diabetesförbundet, Diabetesföreningen Malmö, Konsul Thure Carlsson Fund for Medical Research, Stiftelsen Sigurd och Elsa Goljes Minne, Region Skåne and Funds from the University Hospital Malmö, Sweden.

\section{References}

Aaberg ML, Burch DM, Hud ZR, Zacharias MP (2008) Gender differences in the onset of diabetic neuropathy. Journal of Diabetes \& Its Complications 22:83-87

Adler AI, Boyko EJ, Ahroni JH, Stensel V, Forsberg RC, Smith DG (1997) Risk factors for diabetic peripheral sensory neuropathy. Results of the Seattle Prospective Diabetic Foot Study. Diabetes Care 20:1162-1167

Booya F, Bandarian F, Larijani B, Pajouhi M, Nooraei et al. (2005) Potential risk factors for diabetic neuropathy: a case control study. BMC Neurology 5:24.

Dahlin LB, Shyu BC, Danielsen N, Andersson SA (1989) Effects of nerve compression or ischaemia on conduction properties of myelinated and non-myelinated nerve fibres. An experimental study in the rabbit common peroneal nerve. Acta Physiol Scand 136:97-105

Dahlin LB, Eriksson KF, Sundkvist G (1997) Persistent postoperative complaints after whole sural nerve biopsies in diabetic and non-diabetic subjects. Diabet Med 14:353-356 
Dahlin LB, Stenberg L, Luthman H, Thomsen NO (2008) Nerve compression induces activating transcription factor 3 in neurons and Schwann cells in diabetic rats. Neuroreport 19:987-990

Dahlin LB, Granberg V, Rolandsson I, Rosen I, Dahlin E et al. (2011) Disturbed vibrotactile sense in finger pulps in patients with type 1 diabetes - correlations with glycaemic level, clinical examination and electrophysiology. Diabet Med. In press

Chien HF, Tseng TJ, Lin WM, Yang CC, Chang YC, Chen RC, Hsieh ST (2001) Quantitative pathology of cutaneous nerve terminal degeneration in the human skin. Acta Neuropathol (Berl) 102:455-461

Dyck PJ, Lofgren EP (1968) Nerve biopsy. Choice of nerve, method, symptoms, and usefulness. Med Clin North Am 52:885-893

Dyck PJ, Kratz KM, Karnes JL et al. (1993) The prevalence by staged severity of various types of diabetic neuropathy, retinopathy, and nephropathy in a population-based cohort: the Rochester Diabetic Neuropathy Study. Neurology 43:817-824

Goransson LG, Mellgren SI, Lindal S, Omdal R (2004) The effect of age and gender on epidermal nerve fiber density. Neurology 62:774-777

Granovsky Y, Matre D, Sokolik A, Lorenz J, Casey KL (2005) Thermoreceptive innervation of human glabrous and hairy skin: a contact heat evoked potential analysis. Pain 115:238-247

Gupta R, Steward O (2003) Chronic nerve compression induces concurrent apoptosis and proliferation of Schwann cells. J Comp Neurol 461:174-186

Herrmann DN, Griffin JW, Hauer P, Cornblath DR, McArthur JC (1999) Epidermal nerve fiber density and sural nerve morphometry in peripheral neuropathies. Neurology 53:1634-1640

Kelly EJ, Terenghi G, Hazari A, Wiberg M (2005) Nerve fibre and sensory end organ density in the epidermis and papillary dermis of the human hand. Br J Plast Surg 58:774779

Lauria G, Cornblath DR, Johansson O et al. (2005) EFNS guidelines on the use of skin biopsy in the diagnosis of peripheral neuropathy. Eur J Neurol 12:747-758

Loseth S, Stalberg E, Jorde R, Mellgren SI (2008) Early diabetic neuropathy: thermal thresholds and intraepidermal nerve fibre density in patients with normal nerve conduction studies. J Neurol 255:1197-1202

Malik RA, Veves A, Walker D et al. (2001) Sural nerve fibre pathology in diabetic patients with mild neuropathy: relationship to pain, quantitative sensory testing and peripheral nerve electrophysiology. Acta Neuropathol 101:367-374

Malik RA, Tesfaye S, Newrick PG et al. (2005) Sural nerve pathology in diabetic patients with minimal but progressive neuropathy. Diabetologia 48:578-585

Meh D, Denislic M (1994) Quantitative assessment of thermal and pain sensitivity. J Neurol Sci 127:164-169

Neary D, Ochoa J, Gilliatt RW (1975) Sub-clinical entrapment neuropathy in man. J Neurol Sci 24:283-298

Nebuchennykh M, Loseth S, Jorde R, Mellgren SI (2008) Idiopathic polyneuropathy and impaired glucose metabolism in a Norwegian patient series. Eur J Neurol 15:810816 
Nolano M, Crisci C, Santoro L et al. (2000) Absent innervation of skin and sweat glands in congenital insensitivity to pain with anhidrosis. Clin Neurophysiol 111:1596-1601

Nolano M, Provitera V, Crisci C et al. (2003) Quantification of myelinated endings and mechanoreceptors in human digital skin. Ann Neurol 54:197-205

Pan CL, Lin YH, Lin WM, Tai TY, Hsieh ST (2001) Degeneration of nociceptive nerve terminals in human peripheral neuropathy. Neuroreport 12:787-792

Pittenger GL, Ray M, Burcus NI, McNulty P, Basta B, Vinik AI (2004) Intraepidermal nerve fibers are indicators of small-fiber neuropathy in both diabetic and nondiabetic patients. Diabetes Care 27:1974-1979

Quattrini C, Tavakoli M, Jeziorska M et al. (2007) Surrogate markers of small fiber damage in human diabetic neuropathy. Diabetes 56:2148-2154

Reske-Nielsen E, Lundbaek K (1968) Pathological changes in the central and peripheral nervous system of young long-term diabetics. II. The spinal cord and peripheral nerves. Diabetologia 4:34-43

Rubino A, Rousculp MD, Davis K, Wang J, Bastyr EJ et al. (2007) Diagnosis of diabetic peripheral neuropathy among patients with type 1 and type 2 diabetes in France, Italy, Spain and the United Kingdom. Prim Care Diabetes 1:129-134

Smith AG, Russell J, Feldman EL et al. (2006) Lifestyle intervention for pre-diabetic neuropathy. Diabetes Care 29:1294-1299

Sorensen L, Molyneaux L, Yue DK (2006) The relationship among pain, sensory loss, and small nerve fibers in diabetes. Diabetes Care 29:883-887

Sundkvist G, Dahlin LB, Nilsson H et al. (2000) Sorbitol and myo-inositol levels and morphology of sural nerve in relation to peripheral nerve function and clinical neuropathy in men with diabetic, impaired, and normal glucose tolerance. Diabet Med 17:259-268

Thomsen NO, Mojaddidi M, Malik RA, Dahlin LB (2009a) Biopsy of the posterior interosseous nerve: a low morbidity method for assessment of peripheral nerve disorders. Diabet Med 26:100-104

Thomsen, NO, Englund E, Thrainsdottir S, Rosen I, Dahlin LB (2009b) Intraepidermal nerve fibre density at wrist level in diabetic and non-diabetic patients Diabet Med 26: $1120-6$

Thomsen NO, Mojaddidi M, Malik RA, Dahlin LB (2009c) Reduced myelinated nerve fibre and endoneurial capillary densities in the forearm of diabetic and non-diabetic patients with carpal tunnel syndrome. Acta Neuropathol 118:785-791

Thrainsdottir S, Malik RA, Rosen I et al. (2009) Sural nerve biopsy may predict future nerve dysfunction. Acta Neurol Scand 120:38-46

Treede RD, Meyer RA, Raja SN, Campbell JN (1995) Evidence for two different heat transduction mechanisms in nociceptive primary afferents innervating monkey skin. J Physiol 483 ( Pt 3):747-758

Umapathi T, Tan WL, Loke SC, Soon PC, Tavintharan S, Chan YH (2007) Intraepidermal nerve fiber density as a marker of early diabetic neuropathy. Muscle Nerve 35:591598 
Veves A, Malik RA, Lye RH et al. (1991) The relationship between sural nerve morphometric findings and measures of peripheral nerve function in mild diabetic neuropathy. Diabet Med 8:917-921 


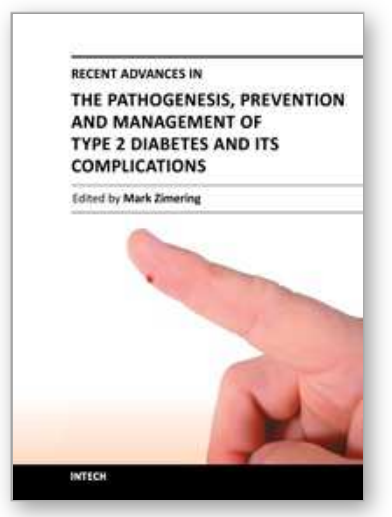

\author{
Recent Advances in the Pathogenesis, Prevention and \\ Management of Type 2 Diabetes and its Complications \\ Edited by Prof. Mark Zimering
}

ISBN 978-953-307-597-6

Hard cover, 442 pages

Publisher InTech

Published online 29, August, 2011

Published in print edition August, 2011

Type 2 diabetes â€œmellitusâ€ affects nearly 120 million persons worldwide- and according to the World Health Organization this number is expected to double by the year 2030. Owing to a rapidly increasing disease prevalence, the medical, social and economic burdens associated with the microvascular and macrovascular complications of type 2 diabetes are likely to increase dramatically in the coming decades. In this volume, leading contributors to the field review the pathogenesis, treatment and management of type 2 diabetes and its complications. They provide invaluable insight and share their discoveries about potentially important new techniques for the diagnosis, treatment and prevention of diabetic complications.

\title{
How to reference
}

In order to correctly reference this scholarly work, feel free to copy and paste the following:

Niels Thomsen, Anders Bjorkman and Lars B. Dahlin (2011). Diabetic Neuropathy - Nerve Morphology in the Upper Extremity, Recent Advances in the Pathogenesis, Prevention and Management of Type 2 Diabetes and its Complications, Prof. Mark Zimering (Ed.), ISBN: 978-953-307-597-6, InTech, Available from:

http://www.intechopen.com/books/recent-advances-in-the-pathogenesis-prevention-and-management-of-type2-diabetes-and-its-complications/diabetic-neuropathy-nerve-morphology-in-the-upper-extremity

\section{INTECH}

open science | open minds

\section{InTech Europe}

University Campus STeP Ri

Slavka Krautzeka 83/A

51000 Rijeka, Croatia

Phone: +385 (51) 770447

Fax: +385 (51) 686166

www.intechopen.com

\section{InTech China}

Unit 405, Office Block, Hotel Equatorial Shanghai

No.65, Yan An Road (West), Shanghai, 200040, China 中国上海市延安西路65号上海国际贵都大饭店办公楼 405 单元

Phone: +86-21-62489820

Fax: $+86-21-62489821$ 
(C) 2011 The Author(s). Licensee IntechOpen. This chapter is distributed under the terms of the Creative Commons Attribution-NonCommercialShareAlike-3.0 License, which permits use, distribution and reproduction for non-commercial purposes, provided the original is properly cited and derivative works building on this content are distributed under the same license. 